\title{
Five Basic Connotations of Xi Jinping's Outlook on Scientific and Technological Innovation
}

\author{
Lindan Liu \\ School of Marxism \\ Wuhan University of Science and Technology \\ Wuhan, China 430065
}

\begin{abstract}
The ideological essence of outlook on scientific and technological innovation proposed by $\mathrm{Xi}$ Jinping is the continuation and development of innovative concept of Marxism. This article analyzes the five basic connotations of outlook on scientific and technological innovation comprehensively, including outlook of status, strategy, development, talent and ecology. Reasonably exploring and deeply understanding its connotation can not only promote the reform of science and technology system in China, but also provide theoretical basis and practical value for building an innovative country.
\end{abstract}

Keywords-Xi Jinping; innovation; outlook on scientific and technological innovation; scientific connotation

\section{INTRODUCTION}

$\mathrm{Xi}$ Jinping's outlook on scientific and technological innovation refers to the doctrine system of scientific innovation and technological innovation formed in the process of governing the country by Xi Jinping. His thoughts on science and technology mainly expound the issue of science and technology innovation in China from five aspects: status, development, strategy, talent and ecology, which points out the direction for the development of science and technology in China.

\section{VIEW ON STATUS OF SCIENCE AND TECHNOLOGY INNOVATION: PUTTING SCIENCE AND TECHNOLOGY INNOVATION AT THE CORE OF THE OVERALL NATIONAL DEVELOPMENT}

Scientific and technological innovation is nominally a matter within the field of science and technology, but it always affects the economic and social development of China. Comrade $\mathrm{Xi}$ Jinping has repeatedly stated the importance of scientific and technological innovation and its significance to China and laid the important position of science and technology innovation in China and the future developing trend by combining the economic and social development in China. He proposed that the center of national development should be placed on scientific and technological innovation, and the customization and design of innovation-driven development strategy should be optimized. When there is an important task, a relevant timetable and roadmap need to be developed. It not only points out the way forward for the implementation of innovation-driven strategy in China, but also provides a more detailed analysis of China's overall innovation planning. The core status of scientific and technological innovation is mainly reflected in following aspects.

\section{A. Science and Technology Innovation is Regarded as the Key Factor of Sustainable Economic Development}

China's economic aggregate ranks second in the world, and the manufacturing industry is even bigger in scale, which ranks first in the world. However, the development of these two aspects has increased the consumption of resources and ecological environment, which constrains the economic development. In the future, we must focus on sustainable development and reduce the imbalance in development. Therefore, from a global perspective, $\mathrm{Xi}$ Jinping further affirmed that scientific and technological innovation is a "focal point". Only by holding this "focal point" influencing the overall situation can we guide the economic development in China to move forward in the right path. Only by catching up with the pace of internationalization in science and technology can we promote the adjustment and optimization of the overall economic structure and fundamentally change its mode of growth, providing strong technological support for the sustainable and healthy economic and social development of China.

\section{B. Technological Innovation is the Strategic Support for Improving Social Productivity and Overall National Strength}

Since the financial crisis, the process of world economic recovery was difficult and tortuous, and the demand of international market was shrinking. Under the circumstances of this crisis, all countries in the world, especially the developed countries, didn't slow the pace of scientific and technological innovation, but further strengthened the strategic role of scientific and technological innovation in the process of recovering and promoting economic growth, so strategic high-tech and related industries have increasingly become the key points in the competition of overall national strength of countries in the world. It can be seen from small countries such as Japan, South Korea, Switzerland, and Singapore that they have promoted the advancement of high technology on the basis of scientific and technological innovation, and at the same time have many outstanding achievements in both science and technology and economy, 
so that they can rank stable in the global science and technology competition. In order to enhance China's scientific and technological competitiveness, Comrade $\mathrm{Xi}$ Jinping emphasizes that scientific and technological innovation should be placed at the core of the national development overall situation at the 18th CPC National Congress. That is to say, we should regard "scientific and technological innovation" as the key object based on profoundly judging the development trend of the international community to maximize the promotion of potential of social productive forces in China.

\section{STRATEGIC CONCEPT OF SCIENTIFIC AND TECHNOLOGICAL INNOVATION: IMPLEMENTING INNOVATION-DRIVEN DEVELOPMENT STRATEGY AND TAKING THE ROAD OF INDEPENDENT INNOVATION}

Since the 1980s, science and technology have been rapidly developed in the world. Several breakthroughs have been made to promote the development of the manufacturing industries in various countries in the world. At the same time, they have affected people's daily production and living style. China, by virtue of its resources and labor force, has promoted industrial development and gradually kept pace with technological innovation of developed countries. However, with the rapid economic development, the past factor-driven development is unbearable for resources and the environment. Comrade $\mathrm{Xi}$ Jinping grasps the overall situation and seizes the crucial point to emphasize that in order to achieve the goal of building a well-off society in an all-round way by 2020; we must implement an innovationdriven development strategy and follow the path of independent innovation with Chinese characteristics.

\section{A. Putting forward the Tasks and Requirements in the Implementation Process of Innovation-driven Development}

First, in the entire process of innovation-driven development strategy, we must give full play to the supporting and leading role of science and technology innovation. Based on the current resource environment and conditions, we must change the past economic development model and shift the development force from element-driving to innovation-driving. The second is to adhere to promoting technological innovation by taking the enterprise as the main body. Because the enterprise is the main body of market competition, the ability of technological innovation can realize the market value only when it becomes the product ability of the enterprise. Innovative ability determines the core competitiveness of enterprises and industries determines the profitability of enterprises and position of the industry in the value chain and affects the voice in international competition. Third, we must grasp the top design and implementation of the task. Comrade Xi Jinping clearly demanded that there be a clear position of the development path of science and technology in China under the current national conditions. At the same time, we should analyze the world's scientific and technological developments from a global perspective. In the face of some major projects, it is necessary to rationally plan time and design routes. Fourth, we must correctly handle the balance between technological innovation and employment. Xi Jinping stressed in particular: "We must unswervingly accelerate innovation as well as implement effective social policies, especially education and social security policies, and solve the problems of enhancing the employability of the working population and guaranteeing basic living issues so as to ensure the overall social stability." [1]18 Fifth, we must vigorously develop the scientific quality of the entire people and mobilize the enthusiasm for innovation and creative vitality that inspire the entire society. Scientific and technological innovation needs good citizen quality to escort. Only by constantly enriching citizens' scientific and cultural qualities can the source of power and energy of people's innovation and creation fully flow. Development is a matter for the whole society, which requires active efforts and joint participation of all people in the society.

\section{B. Pointing out that We Should Unswervingly Follow the Path of Independent Innovation}

With the constant globalization, informationization and networking of current world economy, economic society of China have changed from the initial manufacturing to the innovation-driving in recent years. At this crucial moment, solving the transformation from original "running behind" toward "parallel running" or even to "leading the way" is a daunting task faced by the broad scientific and technological work. In order to win the initiative in the global technological competition, we must stick to the path of independent innovation. On the one hand, it reflects in the mastery of the core technology. Science and technology are the driving force behind the prosperity of a country. It is very difficult to obtain the true technical core through normal trade. Comrade Xi Jinping reminds science and technology workers that "we cannot always dress up our tomorrow with the help of other people. We cannot always count on the scientific and technological level of others, let alone the technological dependency of other countries, and can't always follow other people's steps." [2] Prosperity of a country needs to introduce and absorb advanced technologies of developed countries. On the basis of this, we cons should constantly improve the capability of independent innovation and firmly grasp the core technologies in our hands. On the other hand, it requires reasonable layout, advanced planning, and the mastery of commanding height and initiative. $\mathrm{Xi}$ Jinping attaches great importance to this issue and stresses that it is necessary to "select right strategic areas and priorities that is related to the overall situation and long-term development" [2], and rationally utilize the basic and common technologies, cutting-edge technologies and asymmetric "killer" to achieve a major breakthrough in key technologies and accelerate the pace of catching up. Finally, we must make good use of the magic weapon of the socialist system. "Self-reliance" and "Concentrating on Great Events" is a magic weapon for the development of science and technology, which can't be abandoned. "Bombs and one satellite" and the development of space technology rely on these two magic weapons, and technological innovation cannot do without this magic weapon. Faced with such a grim situation in the development of China, during his 
inspection tour in Shanghai, Xi Jinping warns us not to belittle ourselves. "We must have confidence in the world's advanced level. This also comes from the confidence of our roads, theories, institutions and cultures." [3]

\section{OUTLOOK ON DEVELOPMENT OF SCIENTIFIC AND TECHNOLOGICAL INNOVATION: REMOVING INSTITUTIONAL OBSTACLES AND ACCELERATING THE PACE OF TECHNOLOGICAL DEVELOPMENT}

The deep-seated contradictions and problems that restrict the economic development of China with the development of science and technology also emerge. The reform of the scientific and technological system has plunged into the "deep water" area where "a slight move in one part may affect the situation as a whole". At present, the most urgent task in implementing the innovation-driven development strategy and enhancing the capability of independent innovation is to remove institutional obstacles, break the bottleneck restricting the sustainable development of economy, maximize the emancipation and stimulation of potential of science and technology as the primary productive force and provide system guarantee for building national innovation system with Chinese characteristic.

On the specific path of breaking the institutional mechanism, he mainly proposes the following requirements:

- Highlighting the dominant position of enterprises in technological innovation and promoting industrial collaborative innovation through market allocation. In the past, investment in science and technology innovation mainly based on scientific research institutes and institutions of higher learning could no longer meet the needs of the current economic development. We need to make the enterprise change from "passive" to "active" and become the true "policy maker" for technological innovation and encourage enterprises to increase R \& D investment, especially science and technology small, medium and micro-sized enterprises to play their own advantage of flexible adaption to rise in the market competition. Through the rational allocation of markets, enterprises, universities, research institutes and financial institutions form an innovative situation of "combining production, learning and research, linking the upper, middle and lower reaches, and cooperating with large, medium and small-sized enterprises" [1] 61.

- Opening up the system and mechanism barrier of the transformation of scientific and technological achievements so as to promote the transfer of scientific research achievements to the real technologies. Technological achievements can realize its value only if they are brought from the laboratory to the market. It is necessary to deepen the cooperation in production, teaching and research, and "set up a innovation chain around the industry chain and improve the capital chain around the innovation chain" [2] so as to realize the smooth transfer of scientific and technological achievements to the economic society.

- Improving the science and technology planning system and management system so as to reduce the fragmentation, closure and repetition of scientific and technological resources. Comrade Xi Jinping requires that science and technology planning should be strategic, which not only need fully layout, but also should highlight the key point. "We should grasp the strengthening of basic frontier research, strategic high-tech research and social welfare technology as a major foundation project" [4], establish a science and technology management platform where decisionmaking, consulting, executing, evaluating and supervising have clear responsibility, organic interaction and coordination to avoid the "isolated island phenomenon" of scientific and technological innovation, improve the rational allocation of scientific and technological resources, plan and coordinate and open up and share the major national scientific research infrastructure and large-scale scientific research equipment, in order to better serve the community and technology innovation.

- Improving the national macro-control mechanism to create a sound scientific research policy environment. It specifically requires the government should transform its functions, complete the division of labor between the government and market, the central departments and the central and local government. We should strengthen the Party's leadership over scientific and technological work. It no longer directly manages specific scientific research projects. We can establish a unified national science and technology management platform and scientific and technological achievements transformation service platform to strengthen intellectual property protection and tax policies conducive to the development of science and technology enterprises and improve the performance evaluation system and incentive policy.

\section{TALENT CONCEPT OF SCIENTIFIC AND}

\section{TECHNOLOGICAL INNOVATION: STRENGTHENING THE} CONSTRUCTION OF TECHNOLOGICAL TALENT TEAM

At present, the competition in the overall national strength of various countries in the world is fiercer and fiercer. If we say that scientific technology is the primary productive forces, talent is the primary resource. Scientific and technological competition is also the talent competition in the final analysis. "The factor that maintains the stable and harmonious society is talent, and innovative business calls for innovative talent" [2]. The key to promoting independent innovation is also talent. With a long-term vision, Comrade $\mathrm{Xi}$ Jinping proposes new ideas for the construction of scientists and technicians in the current situation and gives full play to the subjective initiative of outstanding personnel. 
A. It Is Necessary to Do a Good Job in Training Domestic Talents as well as Introducing International Innovative Talents

In recent years, the teams of science and technology talents have been continuously expanding. Science and technology innovation cause in China needs to cultivate a high-level and diversified talent system. On the one hand, based on the domestic situation, we should train leading personnel of major scientific research projects, engineering innovation and technology talents of major engineering, elite talent of key disciplines and venture capital entrepreneurs. In particular, it is necessary to focus on cultivating young scientific and technological talents and fully tapping the talents of universities. On the other hand, we need to open our eyes to the whole world, choose the best talents from all over the world to use, strive to attract international talents and gives them more opportunities and room to play their respective specialties and participate in the development of science and technology in China.

\section{B. To Reform and Perfect the Institutional Mechanisms for the Development of Talents so as to Create a Scientific and Technological Innovation Environment for Scientists and Technicians}

While affirming the grand scale of China's scientific and technological personnel, Xi also raises the issue of "level" and "structure" confronting China's scientific and technological personnel. To solve this problem, firstly we need to make full use of talents, stimulate the great potential of innovative talents, and improve the mechanisms for talents development, such as the discovery mechanisms, management mechanisms and evaluation mechanisms to stimulate their innovative vitality and "encourage the social morality of recognizing talents, loving talents, respecting talents and using talents in our society". Second, it is necessary to deepen the reform of education system, enhance the quality of personnel training, and pave the way for young talents to play their role and show their talents so that the training direction of university personnel can be connected closely with businesses and markets to promote the fast transformation of scientific achievements. Thirdly, it is necessary to improve institutional mechanisms for the introduction of talents, attract overseas experts and talented people with major science and technology projects, and at the same time, pay attention to the application of property right, protection mechanism and innovation of incentive mechanism for overseas talent; we can follow the flow regularity of international talents to promote the rational and orderly flow of human resources, and "create a good atmosphere of respecting, caring, and supporting innovation and entrepreneurship of foreign talent" [5] so that they can better serve the cause of innovation in China.

\section{Strengthening the Personal Qualities and Moral Cultivation of Science and Technology Innovative Talent}

High-level innovative talents not only have rich professional knowledge and innovative thinking ability, but also possess outstanding personal qualities and noble moral qualities. $\mathrm{Xi}$ Jinping attaches great importance to the personality cultivation of science and technology workers, so he requires constructing a large-scale, high-quality, all-round development innovative personnel. He points out that the most important thing for scientists and technicians is "to have a strong sense of patriotism" [6]. they should bear in mind the interests of the country and the people, inherit the traditional virtue of "worrying for the world ahead of the people and enjoy the fruits after the people" and inherit the fine quality of patriotic dedication and indifferent to the fame and fortune of the older generation of scientists"[6] to leave the scientific and technological achievements in the motherland and closely link the ideal and "the Chinese dream".

\section{ECOLOGICAL VIEW OF SCIENCE AND TECHNOLOGY INNOVATION: GREEN TECHNOLOGY IS AN IMPORTANT MEANS FOR MANKIND TO BUILD A BEAUTIFUL EARTH}

Marx believed that mankind and nature have the internal logic relationship of complement and mutual influence. He generously complimented the tremendous progress made by the rapid development of science and technology in the development of human productivity when he acutely discovered the negative impact brought by the alienation of science and technology. It is believed that science and technology activities are gradually amplifying the conflict between human and nature and humankind begins to face a more serious ecological crisis than ever before. Over the more than 30 years since the reform and opening up, with the rapid growth of CDP in China, it also faces the grim situation of tight resource constraints, serious environmental pollution and ecosystem degradation. So, how can we achieve green development and build an ecological civilization? The party's leading groups have attached great importance to this issue and raised the building of ecological civilization to a strategic height for national development. They have also included it in the "five in one" general layout of the cause of building socialism with Chinese characteristics at the 18th CPC Congress and called for the whole society to protect the ecological environment and build a better home.

\section{A. Green Technology Is an Important Technical Guarantee for Environmental Protection and Ecological Construction}

Comrade Xi Jinping profoundly pointed out early at the Boao Forum for Asia in April 2010: "we should speed up the development of low-carbon technologies, promote efficient energy-saving technologies, and increase the proportion of new and renewable sources of energy to provide strong technical support for green development and sustainable development of Asian countries." [7] In October 2015, at the Fifth Plenary Session of the 18th Party Central Committee, he put forth the concept of green development and set a correct ecological concept to unify the economic development with environmental protection. He emphasized that this is "the only way for inner request of the future development of China and construction of socialist ecological civilization." [8] On the basis of inheriting the achievements of the previous generations of leader groups, a new viewpoint was put forward: "Green technology ... is an 
important means for mankind to build a beautiful planet" [9], which puts a "green" coat on technological development, highlights the intrinsic value of scientific and technological innovations and enriches and develops the Marxism ecological outlook on science and technology innovation. Green science and technology carries a new type of relationship between man and nature. Currently, it is generally defined as "the general term for scientific and technological activities that promote the long-term survival and sustainable development of mankind in the long run and the coexistence of man and nature" by academic world, and even some scholars predict that green technology will become the engine driving a new round of industrial revolution.

\section{B. Relying on Green Technology to Efficiently and Reasonably Allocate Resources}

How can we transform the vision of "Beautiful China" into reality? General Secretary Xi asks us to change the way we used to rely mainly on resources and investment to drive economic growth. Instead, we should accelerate the rapid improvement of production efficiency with technological applications and technological innovations. We can make use of green technologies innovation to efficiently and reasonably allocate various resources, save energy and reduce emissions, and promote the upgrading and transformation of eco-industries and green industries so as to maintain the balance between economic development and green development. Only when economic development and environmental protection work together and complement each other can we build the beautiful homeland with blue sky and white clouds, green mountains, and harmonious development of man and nature.

\section{CONCLUSION}

$\mathrm{Xi}$ Jinping's concept of scientific and technological innovation is not only a combination of scientificity and systematicness but also a combination of inheritance and innovation as well as an organic part of socialist theoretical system. It answers the questions and countermeasures that the reform and opening up faces when entering the crucial period and deep-water areas from the theoretical and practical aspects, takes scientific and technological innovation as the endogenous driving force for economic development and implement the innovation-driven development strategy throughout the modernization construction. Only in this way can national competitiveness have solid support to continuously lead the socialism with Chinese characteristics to go forward in the scientific track.

\section{REFERENCES}

[1] Xi Jinping. Excerpts from Discourse on Technological Innovation. Beijing: Central Party Literature Press, 2016.

[2] Xi Jinping. Speech at the 17th Academician Conference of Chinese Academy of Sciences and the 12th Academician Conference of Chinese Academy of Engineering. People's Daily, 2014-06-09(2).

[3] Unswervingly follow the road of independent innovation with Chinese characteristics. Xinhua, (2016-02- 28).http://news.xinhuanet.com/politics/201602/28/c_128754803_2.htm.

[4] Xi Jinping. Speech of the Political Bureau of the CPC Central Committee during the Ninth Collective Study. People's Daily, 201310-2(2).

[5] Xi Jinping. Speech in the discussion with foreign experts. People's Daily, 2015-05-24(2).

[6] Xi Jinping. Speech at the Chinese Academy of Sciences. People's Daily, 2013-07-18(2).

[7] Xi Jinping. Work hand in hand to promote green development and sustainable development in Asia. People's Daily, 2010-04-11(2).

[8] Xiao Anbao, Wang Lei. On Xi Jinping's Thought of Green Development - from the Fifth Plenary Session of the 18th Central Committee of the Party. Changbai Journal, 2014(2): 82-88.

[9] Xi Jinping. Let engineering and technology benefit mankind and create future. People's Daily, 2014-06-04(2). 